\title{
Strategies to Mitigate Declines in the Economic Value of Wind and Solar at High Penetration in California
}

\author{
Andrew D. Mills ${ }^{\mathrm{a}, *}$, Ryan H. Wiser ${ }^{\mathrm{a}}$ \\ ${ }^{a}$ Lawrence Berkeley National Laboratory, 1 Cyclotron Rd. MS90-R4000, Berkeley, CA \\ 94720
}

\begin{abstract}
Previously, we quantified a decline in the marginal economic value of wind and PV with increasing penetration levels based on a long-run equilibrium investment and dispatch model that accounted for operational constraints for conventional generation. We use the same model and data, based loosely on California in 2030 , to evaluate several options to stem the decline in value of these technologies. The largest increase in the value of wind at high penetration levels comes from increased geographic diversity. The largest increase in the value of $\mathrm{PV}$ at high penetration levels comes from assuming that low-cost bulk power storage is an investment option. Other attractive options, particularly at more modest penetration levels, include real-time pricing and technology diversity. Keywords: economic valuation, real-time pricing, storage, renewable integration
\end{abstract}

\section{Introduction}

Broadly, two approaches are used to determine how much investment to make in generation capacity: centralized planning and decentralized markets. The decisions in the centralized planning approach are often based on cost5 minimizing capacity expansion models [1] whereas decisions in the decentralized market approach are based on maximizing profitability with expected wholesale

\footnotetext{
${ }^{*}$ Corresponding author

Email address: admills@lbl.gov (Andrew D. Mills )
}

Preprint submitted to Applied Energy

March 6, 2015 
power prices [2]. Based on these two approaches, it is possible to develop criteria for increasing investments in variable renewable generation (VG) like wind and solar photovoltiacs (PV). In the centralized approach the addition of VG can contribute to minimizing overall system costs when the marginal value is greater than the cost of VG [3]. In the decentralized approach the addition of VG contributes to maximizing profits when the net revenue earned from selling generation exceeds the cost of VG 4]. Though the specifics between these two approaches differ, these criteria have many similarities. At a high level, the comparison of benefits to costs is key to understanding investment decisions in decentralized markets or recommended investments from capacity expansion models.

For a given cost of $\mathrm{VG}$, the optimal investment is up to the point where the marginal value curve intersects with the cost curve, Figure [1 Increases in the marginal value (i.e., shifting the value curve up), without changing the costs, will increase the optimal quantity of investment, while decreases in the marginal value (i.e., shifting the value curve down) will decrease the optimal quantity. While the costs of wind and PV are well documented [e.g., 5, 6, 7, the marginal value of wind and PV with increasing penetration levels is less understood, though the body of literature on the subject is growing [e.g., 8, 9].

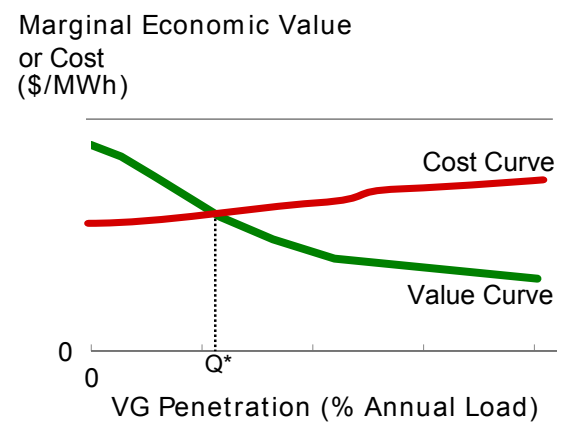

Figure 1: Illustration of investment criteria for variable generation

The purpose of this paper is to evaluate methods that can help maintain 
the value of wind and PV with increasing penetration. Previously, we used a case study of increasing penetration of wind and PV in California to quantify a decline in marginal value and to understand drivers of the changes in value so [10, 11. We found that the changes in value with increasing penetration, Figure 2. were primarily driven by decreases in energy value or capacity value. The costs associated with forecastability and short-term variability of wind and PV did not change as much with increasing penetration levels. The quantitative results from that study are summarized in Table 1 and 2. The details of the method used to decompose the marginal value is described in Section 2, Similar conclusions are summarized by Hirth (2013) both based on results from other modeling studies and based on empirical analysis of actual market impacts in Germany [8. Findings from that research support the conclusion by Mills \& Wiser (2012) [10] that the marginal value of PV is higher than the value of wind 40 at low penetration, but that the marginal value drops at a faster rate for PV with increasing penetration.

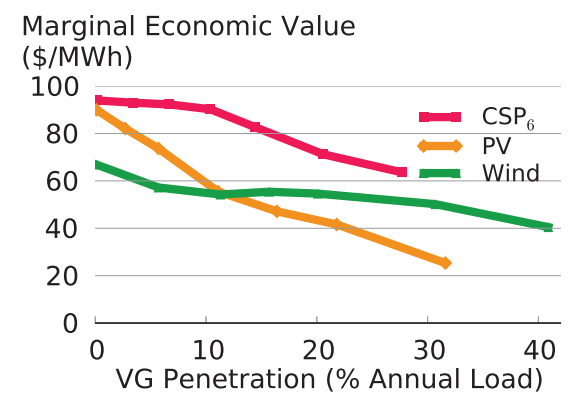

Figure 2: Marginal economic value of wind, PV, and CSP with thermal storage found in the Reference scenario of Mills \& Wiser (2012) [10].

The relatively rapid drop in the value of PV is largely due to decreases in capacity value with increasing penetration. As PV penetration increases, the period of system need shifts into hours with low solar generation, decreasing 45 the marginal contribution of solar to resource adequacy. Similar rates of de- 
Table 1: Decomposition of the marginal economic value of Wind in 2030 with increasing penetration

\begin{tabular}{|c|c|c|c|c|c|c|c|}
\hline \multirow{2}{*}{$\begin{array}{l}\text { Component } \\
\text { (\$/MWh) }\end{array}$} & \multicolumn{7}{|c|}{ Penetration of Wind } \\
\hline & $0 \%$ & $5 \%$ & $10 \%$ & $15 \%$ & $20 \%$ & $30 \%$ & $40 \%$ \\
\hline+ Capacity Value ${ }^{a}$ & (69) 17 & (37) 12 & (30) 10 & (30) 10 & (28) 9 & $(25) 8$ & $(25) 8$ \\
\hline + Energy Value & 50 & 49 & 48 & 48 & 48 & 46 & 39 \\
\hline+ DA Forecast Error & -0.4 & -3 & -4 & -2 & -2 & -3 & -6 \\
\hline + Ancillary Services & -0.4 & -0.2 & -0.2 & -0.2 & -0.2 & -0.2 & -0.2 \\
\hline$=$ Marginal Economic Value & 67 & 57 & 54 & 55 & 54 & 50 & 40 \\
\hline \multicolumn{8}{|c|}{ a - Capacity value is reported in $\$ / \mathrm{kW}$-yr terms in parentheses. } \\
\hline Curtailment (\% of Wind) & $0.0 \%$ & $0.0 \%$ & $0.0 \%$ & $0.0 \%$ & $0.0 \%$ & $0.3 \%$ & $3.2 \%$ \\
\hline
\end{tabular}

Table 2: Decomposition of the marginal economic value of PV in 2030 with increasing penetration

\begin{tabular}{|c|c|c|c|c|c|c|c|}
\hline \multirow{2}{*}{$\begin{array}{l}\text { Component } \\
(\$ / \mathrm{MWh})\end{array}$} & \multicolumn{7}{|c|}{ Penetration of PV } \\
\hline & $0 \%$ & $2.5 \%$ & $5 \%$ & $10 \%$ & $15 \%$ & $20 \%$ & $30 \%$ \\
\hline+ Capacity Value ${ }^{a}$ & (120) 37 & (110) 34 & (82) 27 & (39) 13 & (24) 8 & (11) 4 & (4) 1 \\
\hline + Energy Value & 54 & 53 & 52 & 49 & 45 & 41 & 27 \\
\hline + DA Forecast Error & -0.2 & -5 & -4 & -6 & -5 & -4 & -3 \\
\hline + Ancillary Services & -0.9 & -0.8 & -0.7 & -0.4 & -0.2 & -0.1 & -0.0 \\
\hline$=$ Marginal Economic Value & 89 & 81 & 73 & 55 & 47 & 41 & 25 \\
\hline \multicolumn{8}{|c|}{ a - Capacity value is reported in $\$ / \mathrm{kW}$-yr terms in parentheses. } \\
\hline Curtailment (\% of PV) & $0.0 \%$ & $0.0 \%$ & $0.0 \%$ & $0.0 \%$ & $0.0 \%$ & $0.1 \%$ & $2.9 \%$ \\
\hline
\end{tabular}


cline of the capacity contribution of PV with increasing penetration have been documented in other studies 3 .

The more modest costs of forecast errors and increased ancillary services have similarly been corroborated with additional research on solar PV forecasting 12], integration studies of solar PV [13], and integration studies of wind [6]. Regions with highly concentrated wind and relatively inflexible generation may see larger costs associated with uncertainty and variability [14].

In this paper, we use the same model and methods as used to estimate the change in the value of wind and PV with increasing penetration in California to examine the degree to which the value of wind or PV increases at different penetration levels when a mitigation strategy is implemented. Changes in the value of wind and $\mathrm{PV}$ with implementation of mitigation strategies can change the optimal investment quantities for wind and PV.

We examine several strategies that have been discussed elsewhere in the literature. Specifically, we examine increased geographic diversity of wind siting 15, 16, 17, 18, technological diversity through combinations of wind and PV [19, 20, 21], lower-cost bulk power storage [22, 23, 24, 8, 25, 26], and priceelastic demand subject to real-time pricing (RTP) [27, 28, 23, 29. Several other strategies are possilbe (e.g., increased interconnection capacity between 65 regions [30, 31]) but are not described here. In some cases we did not examine these other strategies due to limitations of the model (e.g., we did not consider transmission between regions in the model), in other cases we did examine them but did not find notable increases in the value of wind or PV (more details regarding those findings are in Mills \& Wiser (2014) 32]).

The primary contribution of this paper is the quantification of the change in the marginal economic value of wind and PV at various penetration levels when these measures are implemented. The change in value is quantified in a consistent, long-run investment framework that accounts for operational constraints for conventional generation (in contrast to studies that only use short-run production cost models or long-run investment models with limited representation of operational constraints). We use this framework to decompose the economic 
value of wind and PV into different components in order to identify the reasons for the change in the value of wind and PV when the mitigation measure is implemented. Finally, we obtain additional insight by conducting the analysis for both wind and PV which allows us to compare and contrast the impacts.

\section{Methods}

We use the same model and data previously used to examine the changes in the value of variable generation with increasing penetration levels in California by Mills \& Wiser (2012). The model is a generation investment and dispatch model of a power system that accounts for detailed operational constraints (such as part-load inefficiencies, commitment decisions based on forecasts, ramping limits, and minimum generation levels for thermal power plants). Particular aspects of the original model are altered to simulate implementation of the mitigation strategy. We then use the results of the modified model to estimate the marginal value of wind and PV with the mitigation strategy.

The model structure is as follows. For a given load profile, wind or solar penetration level, and set of incumbent generation, the model finds a set of new generation investments that earn sufficient revenue to cover their fixed cost of investment, but that no additional generation would find it profitable to enter (DA) power prices are based on DA forecasts of wind and PV and real-time (RT) prices are based on the actual generation. Revenues for each generator are based on the DA schedule and the DA price with RT deviations from the day-ahead schedule paid at the RT price. The model also calculates DA and RT ancillary services (AS) prices (for regulation, spinning reserve, and non-spinning reserve). The new investment options include natural gas combined cycle gas turbine (CCGT) and combustion turbine (CT) plants as well as coal, nuclear, and pumped-hydro storage (PHS).

For new generation to fully cover its fixed investment and operations and manintenance $(\mathrm{O} \& \mathrm{M})$ costs through the power market, wholesale prices must 
periodically exceed the marginal fuel cost of generation. In some hours, generation will be at its full capacity and unable to meet all of the AS targets, and eventually load will need to be shed involuntarily. The wholesale prices in those hours rise to predefined, administratively set scarcity prices that reflect the need for additional generation at those times. In other hours, excess generation can lead to curtailment of generation. There are no additional penalties or costs associated with curtailment, so prices periodically fall to zero but do not become negative. In effect, the marginal economic value of wind and PV is found by simulating a competitive, "energy-only" power market [2, 33]. The fixed costs of new generation are recovered during times with price spikes rather than relying on side payments from a capacity market.

\subsection{Marginal Economic Value}

The marginal value of wind and PV is based on the revenue earned by selling into the simulated power market in long-run equilibrium. The total revenue is calculated as the sum of the revenue earned by selling forecasted generation into the DA market at the DA price and the revenue earned (or lost) by selling any deviations from the DA forecast in the RT market at the RT price. No punitive imbalance penalties are levied on wind or PV for RT generation that differs from the DA forecast. Instead, deviations from the DA forecast are generally sold at an RT price that is lower than the DA price, or shortfalls in RT generation from the DA forecast are purchased at RT prices that exceed the DA price. In addition, wind and PV are allowed to sell the ancillary service of regulation in the downward direction. Wind and solar are also charged for any assumed increase in the hourly AS requirements due to short-term variability and uncertainty. Following the assumptions in the original model, the regulation reserve requirement is assumed to increase by an amount equivalent to $5 \%$ of the DA forecast of wind and PV in each hour.

To better understand the source of value and the causes of changes in value, we decompose the value into four categories: 
- Capacity Value (\$/MWh): The portion of net revenue earned during hours with scarcity prices (defined to be greater than $\$ 500 / \mathrm{MWh}$ ).

- Energy Value (\$/MWh): The portion of net revenue earned in hours without scarcity prices, assuming the DA schedule exactly matches the RT generation.

- Day-ahead Forecast Error (\$/MWh): The net earnings from RT deviations from the DA schedule.

- Ancillary Services $(\$ / M W h)$ : The net earnings from selling AS in the market from wind or PV and paying for increased AS due to increased short-term variability and uncertainty from wind or PV.

The resulting estimate of the marginal economic value is based only on a subset of the benefits of adding VG. The subset of the benefits is primarily based on avoiding the capital investment cost and variable fuel and O\&M costs from other (fossil-fuel-based) power plants in the power system. These avoided costs are calculated while accounting for operational constraints on conventional generators and the increased need for AS when adding VG. The analysis does not consider many other costs and impacts that may be important, including environmental impacts, transmission and distribution costs or benefits, effects related to the "lumpiness" and irreversibility of investment decisions, and uncertainty in future fuel and investment capital costs.

\subsection{Case Study of California in 2030}

The case study loosely matches characteristics of California projected to 2030. These characteristics of California include generation profiles for wind and PV, existing generation capacity, and the hourly load profile. Thermal generation parameters and constraints (e.g., variable O\&M costs, the cost of fuel consumed just to have the plant online, the marginal variable fuel cost associated with producing energy, start-up costs, limits on how much generation can ramp from one hour to the next, and minimum generation limits of generation that is 
online) are largely derived from observed operational characteristics of thermal generation in the Western Electricity Coordinating Council (WECC) region, averaged over generators within the same vintage. Aside from fossil-fuel-fired generation, the existing generation modeled in California includes geothermal, hydropower, and pumped-hydro storage (PHS). California load and conventional generation is treated in isolation from any other load or conventional generation in the rest of WECC. In other words, we do not consider existing or future transmission capacity between California and the rest of WECC, except for imports of wind and PV to serve California loads. Fossil-fuel prices are based on the fuel prices in 2030 in the EIA's Annual Energy Outlook 2011 reference case forecast 34 .

\subsection{Change in Value with Mitigation Strategy}

The primary question in evaluating each mitigation strategy is: If this mitigation strategy were to be implemented, how would it change the value of VG relative to an unmitigated case?

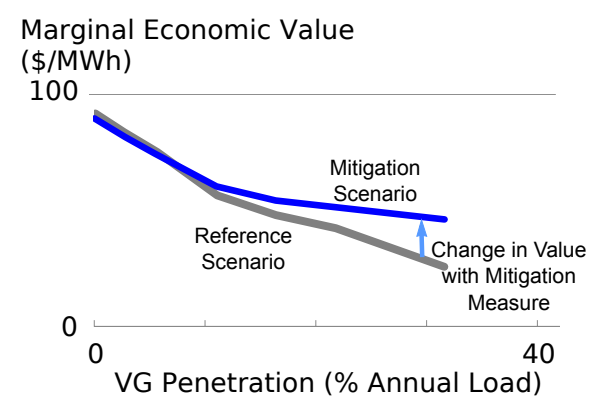

Figure 3: Change in the value of VG after implementation of a mitigation strategy is defined in relation to the value in the unmitigated Reference scenario in Mills \& Wiser (2012) [10].

We calculate the impact of the mitigation strategy on the value of wind or $\mathrm{PV}$ by finding the difference between the marginal value of wind or PV 180 after implementing the mitigation strategy relative to the marginal value of wind or PV at the same penetration level without the mitigation strategy, as 
illustrated in Figure 3. We refer to the case without the implementation of the mitigation strategy as the Reference scenario. To make this comparison, we use new scenarios in which a mitigation strategy is implemented, find new longrun equilibrium investments and wholesale prices with that mitigation strategy, and then recalculate the value of wind or PV in that new long-run equilibrium. An increase in the value of wind or PV with the mitigation strategy relative to the case without the mitigation strategy signals that the mitigation strategy can help moderate the decline in the value of wind or PV with increasing penetration found in earlier studies.

\section{Results and Discussion}

For each of the mitigation methods we first provide more detail on how the strategy was implemented in the model, we then present the estimated change in the value of wind or PV with the implementation of the strategy, explore the reasoning for the observed changes, and any additional considerations that help understand the potential effectiveness of the mitigation strategy.

\subsection{Geographic Diversity}

The geographic diversity mitigation strategy is based on siting wind plants in locations that minimize the variance of the aggregate wind production. This leads to wind sites being much more geographically distant from one another relative to the wind sites in the Reference scenario 1

Wind sites in the Reference scenario were selected from resource hubs identified in the Western Renewable Energy Zone (WREZ) Initiative [35. These resource hubs are assumed to have a finite capacity available for building wind plants. As the penetration of wind was increased in the Reference scenario, wind sites from additional WREZ hubs were included in the wind portfolio. As

\footnotetext{
${ }^{1}$ Geographic diversity of PV is not considered since variability from clouds has little to do with the decline in the value of PV with increasing penetration.
} 
a consequence, a certain amount of geographic diversity is already reflected in the Reference scenario.

In this mitigation analysis, we develop an alternative wind portfolio in which wind sites are selected using only the criteria that the sites are geographically diverse (based on the approach outlined by Palmintier et al. (2008) [36]). We use increasing wind penetration at these high-diversity sites to find new investment and dispatch decisions and long-run equilibrium power prices. We then compare the marginal value of wind in this Diverse scenario to the marginal value of wind in the Reference scenario. For illustration purposes, we similarly find the change in the marginal value of wind in a scenario that concentrates all of the wind sites in one region. In this Concentrated scenario, the wind sites are located at WREZ hubs in and around Southern California 2

\subsubsection{Change in Value} nario's portfolios increases the marginal value of additional wind by about $\$ 5 / \mathrm{MWh}$ at moderate penetration $(10 \%)$ and high penetration (30\%). At very high penetration, the Diverse scenario's portfolio increases the marginal value of additional wind by more than $\$ 10 / \mathrm{MWh}$, Figure 4 (27\% increase in the marginal value of wind relative to the value in the unmitigated scenario with $40 \%$ wind penetration). At $40 \%$ wind, increased geographic diversity leads to the largest increase in the value of wind when compared to the other mitigation strategies examined in this analysis.

In contrast, concentrating the wind sites in one geographic region decreases the value of wind relative to the Reference scenario. Concentrating wind sites decreases the value of additional wind by around $\$ 6 / \mathrm{MWh}$, with wind penetration up to 40\%, as also shown in Figure 4 .

\footnotetext{
${ }^{2}$ In the Concentrated scenario, we ignore constraints identified in the WREZ Initiative in terms of how much wind could be sited in a particular region.
} 


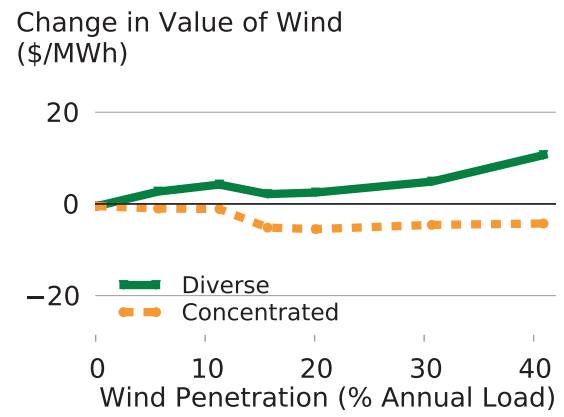

Figure 4: Change in the marginal economic value of wind with geographically concentrated or diverse wind sites relative to the Reference scenario.

\subsubsection{Reasons for Change}

Detailed analysis of the Diverse scenario's wind portfolios indicates that the increase in value relative to the Reference scenario is primarily based on an increase in the capacity value for penetrations below $30 \%$. At $40 \%$ penetration, the increase in the value of wind for the Diverse scenario's portfolio is due to an increase in energy value followed by a smaller increase in the capacity value and a small decrease in the DA forecast error cost. The increase in energy value is in part due to a reduction in curtailment in the Diverse scenario. Over $3 \%$ of the annual wind is curtailed at $40 \%$ wind penetration in the Reference scenario, but less than $0.1 \%$ is curtailed in the Diverse scenario.

A portfolio with high geographic diversity leads to a higher value of wind due to a reduction in extremes: fewer hours have significant amounts of wind from all wind sites in the portfolio (reducing over-generation and curtailment), and more hours have at least a small amount of wind generation from some sites. The benefit of increased geographic diversity is more pronounced with high wind penetration levels since wind is more likely to affect wholesale prices at high penetration levels.

Concentrating wind in one region tends to increase the frequency of extremes, where all wind is generating or no wind is generating. Increases in wind generation tend to occur simultaneously in areas where wind speeds are already 
high and thus while wholesale prices are already low (due to the surplus wind generation). Similarly, wind forecast errors tend to be correlated when wind sites are concentrated. The lower value in the Concentrated scenario is driven primarily by an increase in the DA forecast error cost. Since large forecast errors can be technically challenging to manage, concentrated wind also raises concerns about secure system operations.

\subsubsection{Further Considerations}

260

With increasing penetration, wind at geographically diverse sites could earn higher revenue than wind sited closer to existing wind. This increase in the value of wind will need to be weighed against any increased costs due to additional transmission or lower wind quality associated with these alternative sites.

Given the potential wide variation in wind quality and access to transmission capacity, considerations about geographic diversity are not likely to dominate siting decisions at present. Wind resource quality and transmission availability are likely to be more important factors. In regions with more correlated wind or less flexible generation, however, the importance of geographic diversity may be greater than observed in California (e.g. 14]).

\subsection{Technological Diversity}

The value of wind can depend on the amount of PV included in a scenario, and vice versa. In the Reference scenario, only wind or PV was added at a time while the other was kept at zero penetration whereas the technological diversity strategy explores combinations of wind and PV. First, we estimate the change in the value of wind when the system has $10 \% \mathrm{PV}$ penetration 3 relative to the

\footnotetext{
${ }^{3}$ The choice of $10 \%$ penetration of the second technology is somewhat arbitrary. For the purpose of this analysis the penetration needs to be substantial enough to produce changes in the timing of high and low prices (meaning it needs to be greater than $0 \%$ ) while not being too high to lead to overcrowding (i.e. not as high as $30-40 \%$ penetration). We would expect to seem somewhat similar results for any choice of $5-20 \%$ penetration of the second technology, though we did not test these other choices.
} 
value of wind without PV. Second, we look at the change in the value of PV with $10 \%$ wind penetration.

\subsubsection{Change in Value}

The marginal value of additional wind when $10 \%$ of the energy is served by $\mathrm{PV}$ is greater than without $10 \% \mathrm{PV}$ for wind penetration levels between $0 \%$ and $20 \%$, Figure 5. At $0 \%$ wind penetration, 4 the marginal value of wind is just over $\$ 7 / \mathrm{MWh}$ greater with $10 \% \mathrm{PV}$ than without it; this positive value steadily decreases until it is only slightly greater at $20 \%$ wind penetration. Beyond $20 \%$ wind penetration, the value of additional wind with $10 \%$ PV begins to decrease relative to its value without $10 \%$ PV. For wind penetrations above $20 \%$, adding $10 \% \mathrm{PV}$ is not an effective mitigation strategy and instead can reduce the value of additional wind.

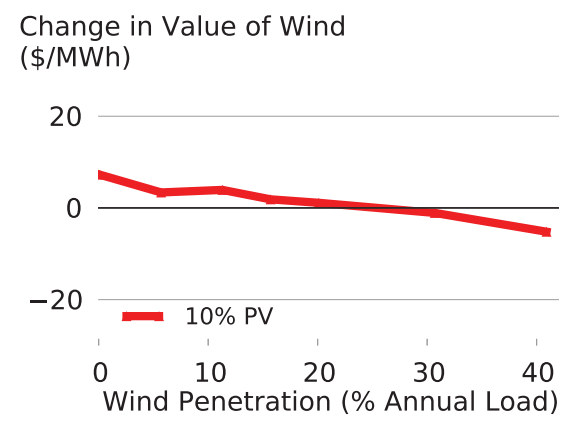

Figure 5: Change in the marginal economic value of wind with $10 \%$ penetration of PV relative to the Reference scenario.

To what degree can adding $10 \%$ penetration of wind mitigate the decline in the value of PV found in the Reference scenario? As shown in Figure 6 at very low PV penetration $(\sim 0 \%)$ the value with or without $10 \%$ wind is similar. However, as PV penetrations increase, adding $10 \%$ wind increases the marginal

\footnotetext{
${ }^{4}$ Every case, even the "No wind/PV" cases, include at least a small amount of wind and $\mathrm{PV}$ so that the marginal value at near $0 \%$ penetration can be estimated.
} 
value of PV substantially relative to the Reference scenario, reaching roughly $\$ 7 / \mathrm{MWh}$ higher at $10 \% \mathrm{PV}$ penetration.

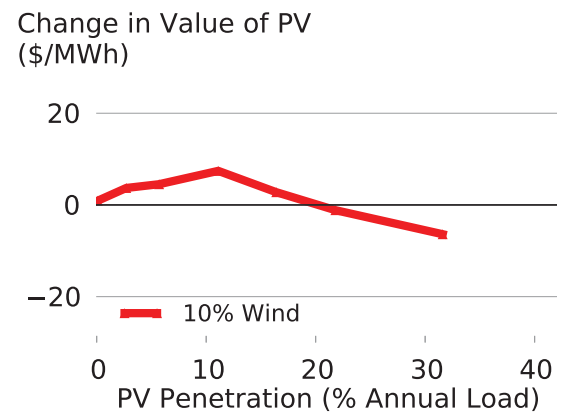

Figure 6: Change in the marginal economic value of $\mathrm{PV}$ with $10 \%$ penetration of wind relative to the Reference scenario.

Above about $10 \%$ penetration of $\mathrm{PV}$, the value of $\mathrm{PV}$ with $10 \%$ wind starts declining toward the value of PV without wind. At 20\% PV penetration, the value of $\mathrm{PV}$ is again similar with or without $10 \%$ wind. At $30 \%$ penetration of $\mathrm{PV}$, the marginal value of $\mathrm{PV}$ with $10 \%$ wind is $\$ 6 / \mathrm{MWh}$ lower than the value of PV without wind. Wind can, therefore, reduce the decline in the value of PV at moderate PV-penetration levels, but not at $20 \%$ or greater PV-penetration levels.

\subsubsection{Reasons for Change}

The increase in the value of $10 \%$ wind with $10 \% \mathrm{PV}$ is largely due to an increase in the capacity value of wind and a slight increase in the energy value of wind. Since the system is in long-run equilibrium with or without the $10 \%$ $\mathrm{PV}$, the average wholesale power prices over the whole year remain at around $\$ 70 /$ MWh (sufficient to cover the investment cost of new CCGT generation). The main difference in the wholesale prices between scenarios with or without $10 \% \mathrm{PV}$ is instead the timing of high or low prices. The increase in the capacity value of wind with $10 \% \mathrm{PV}$ is due to $\mathrm{PV}$ shifting the timing of the peak prices into the early evening, when wind generation is somewhat stronger. While wind 
is not operating at its full capacity during the early evening, it is generating more during that time, on average, thus the value of wind increases with $10 \%$ PV. In contrast, the cost of DA forecast errors for $10 \%$ wind does not change with or without $10 \% \mathrm{PV}$ and curtailment remains at $0 \%$.

The high value of $\mathrm{PV}$ at low penetration is due to the coincidence of $\mathrm{PV}$ generation and scarcity prices in the late afternoon on peak-load days. Wind does not generate much power in the late afternoon, so adding $10 \%$ wind does not substantially affect the timing of scarcity prices and the marginal value of $\mathrm{PV}$ at low penetration. Hence, the value of $\mathrm{PV}$ at $0 \%$ penetration does not vary with the decision to include some wind.

At $10 \% \mathrm{PV}$ penetration, however, the increase in the marginal value of $\mathrm{PV}$ with $10 \%$ wind penetration is due to an increase in the capacity value of PV relative to the Reference scenario. The increase in the capacity value is tied in part to wind generation occurring in early evening. The wind generation in early evening slows the shift of high-price hours into the early evening with increasing PV. In turn, the PV generation continues to occur during times with high prices, increasing its value. The cost of DA forecast errors for $10 \% \mathrm{PV}$ decreases by less than $\$ 1 / \mathrm{MWh}$ with $10 \%$ wind and curtailment remains at $0 \%$.

The decline in the value with technological diversity at very high penetration 330 levels is due to a "crowding-out" effect. When the penetration of one technology is very high, net demand and wholesale prices are frequently very low, lessening the value of additional generation. Increasing overall variable generation further exacerbates this decline in value in hours where both technologies are generating power. This crowding leads to the reduction in value with technological diversity at penetrations above $30 \%$ penetration for wind and above $20 \%$ penetration of $\mathrm{PV}$.

\subsubsection{Further Considerations}

For moderate penetration levels, technological diversity can increase the value of wind or PV relative to a scenario with just one VG technology (though 340 these particular results depend on the correlation of load, wind, and PV in Cal- 
ifornia, which may be different in other regions). Just as importantly, we find a range of penetration levels where wind and solar technologies do not interfere with each other. The value of additional wind at $20 \%$ penetration and $10 \% \mathrm{PV}$ (a total VG penetration of 30\%) is similar to the value of additional wind at $20 \%$ penetration of wind alone. In other words, there is no reduction in economic value of wind at $20 \%$ wind penetration with or without $10 \%$ penetration of PV. At $30 \%$ wind penetration, wind is only slightly less valuable with $10 \%$ PV (a total VG penetration of $40 \%$ ) than without it. Similarly, the value of additional PV at $20 \% \mathrm{PV}$ penetration and $10 \%$ wind (a total VG penetration of $30 \%$ ) is almost equal to the value of additional PV at $20 \% \mathrm{PV}$ penetration alone. This suggests that analysts can evaluate the value of wind or PV at up to $20 \%$ penetration with only one technology at a time, knowing that the value of that technology will not decrease if up to a $10 \%$ penetration of the other variable technology is added.

Taken together, these scenarios indicate that relatively high penetrations of total VG can be achieved using combinations of wind and solar technologies while maintaining or even enhancing the value of the wind/solar generation compared with the value of using single wind and solar technologies in isolation. However, determining whether to pursue technological diversity as a mitigation 360 strategy would require comparing the anticipated increase in value against the potential higher cost of building combinations of technologies to achieve the target penetration level. For example, even though the value of $20 \%$ wind may be lower than the value of $10 \%$ wind and $10 \%$ PV, PV might be more expensive than wind, leading to an overall higher cost. The value changes illustrated in here are an important part of this full consideration. We posited $10 \%$ penetration of the other technology, but the right combination to maximize the benefit of technological diversity is also an important question. Similar analysis where the quantity of variable generation is an endogenous decision could be used to find the combination that leads to long-run equilibrium or that minimizes cost (e.g., 37]). 


\subsection{Low-Cost Storage}

In this section we quantify how much more valuable wind and PV are when low-cost storage is added to the system. Bulk power storage in this section refers specifically to any storage resource that charges using power from the grid and has a round-trip efficiency of $81 \%$. Storage dispatch is optimized concurrently with the dispatch from all other generation options (including conventional generation and hydro). Storage can be charged or discharged and can also provide AS, specifically, regulation (up or down), spinning reserve, and non-spinning

Wiser (2012) [10. The size of the assumed storage reservoir is sufficient to provide power for 10 hours at full nameplate capacity.

The Low-Cost Storage scenario assumes a lower annualized investment cost and fixed O\&M cost equivalent to $\$ 140 / \mathrm{kW}$-yr, approximately $20 \%$ of the cost used in the Reference scenario. This low investment cost is based on the cost estimate for a proposed PHS facility that uses two existing mine pits for the upper and lower reservoirs [38. Since the cost of storage in the Low-Cost Storage scenario is even lower than the annualized fixed cost of a CCGT or CT and new capacity is needed, low-cost storage automatically becomes one of the investment options selected in the model.

With the assumption of low storage-investment costs, $4.4 \mathrm{GW}$ of new storage capacity are built even in the no wind and PV cases. The amount of new storage capacity grows by $57 \%$ with $40 \%$ wind, to the point that the total new and existing storage capacity is $25 \%$ of the nameplate capacity of wind. The existing storage capacity is $38 \%$ of the nameplate capacity of PV.

\subsubsection{Change in Value}

The investments in new storage change the value of wind relative to the Reference scenario with no new storage. Although additional storage increases 
$40 \%$ wind penetration, Figure 7 With $40 \%$ wind, the availability of low-cost bulk power storage leads to an $11 \%$ increase in the value of wind relative to the Reference scenario.

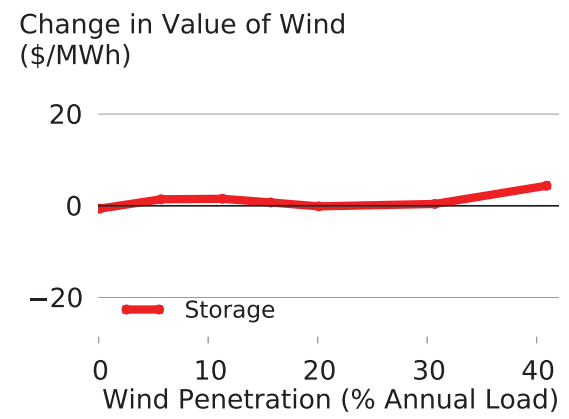

Figure 7: Change in the marginal economic value of wind with low-cost PHS.

At low PV penetration, the value of PV declines modestly with low-cost storage relative to the value of PV in the Reference scenario, Figure 8 . The results are different at higher PV penetrations, where low-cost storage substantially increases the value of PV. Low-cost storage begins to increase PV value relative to the value without low-cost storage at greater than 5\% PV penetration. By $30 \% \mathrm{PV}$ penetration, the marginal value of additional PV is $\$ 20 / \mathrm{MWh}$ greater with low-cost storage than without (an 80\% increase in the marginal value of PV relative to the value in the Reference scenario with $30 \%$ PV penetration).

\subsubsection{Reasons for Change}

The introduction of low-cost storage results in two somewhat competing effects. First, the assumed low cost of storage capacity slightly reduces the capacity value of wind and PV at low penetration levels. Since storage is now the option with the lowest investment cost, it becomes the new capacity resource. Fewer hours with scarcity prices are required to cover the fixed cost of investment in storage compared to the number of hours required to cover the cost of a CCGT. This in turn lowers the capacity value of wind and PV, since those resources now generate less power during periods with scarcity prices. Second, 


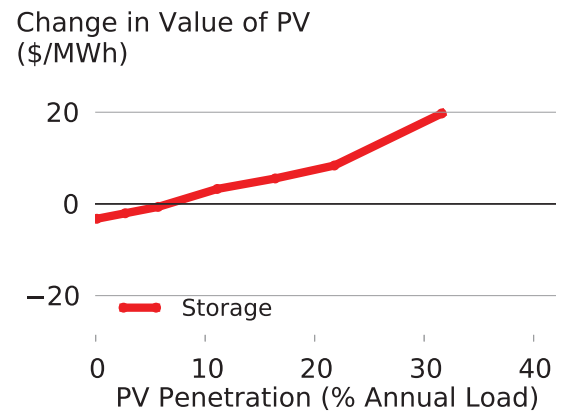

Figure 8: Change in the marginal economic value of $\mathrm{PV}$ with low-cost PHS relative to the Reference scenario.

the increase in storage capacity tends to increase the energy value of wind and PV. Storage, particularly with high penetrations of wind or PV, tends to be charging when wind or $\mathrm{PV}$ is generating, and storage tends to be generating when the wind is not blowing or the sun is down, although this relationship does not always hold for a particular day. The increased demand from charging storage during times with wind and PV generation reduces curtailment and increases energy prices during those times.

At most wind penetration levels, the reduction in capacity value is similar to the increase in energy value, leading to only minor changes in the marginal value of wind. At $40 \%$ wind penetration, the increases in wholesale prices when storage is charging and wind is generating leads to an increase in the energy value of wind. Additionally, the energy value of wind increases in part due to a reduction in wind curtailment from $3.2 \%$ with $40 \%$ wind in the Reference scenario to $0.2 \%$ in the Low-cost Storage scenario. The increase in the energy 435 value with storage is distinctly larger than the reduction in the capacity value. As a result, the marginal value of wind increases by about $\$ 4 / \mathrm{MWh}$ with storage relative to the Reference scenario.

Since the capacity value is a large source of $\mathrm{PV}$ value at low penetration levels, a decrease in the number of hours with scarcity prices, as seen with the introduction of low-cost storage, has a negative impact on the value of PV at 
low penetration. Furthermore, at low PV penetration, storage and PV tend to generate power at similar times, resulting in lower wholesale prices at these times and potentially lower energy value.

With high PV penetration, storage is charging during times with PV generation, which increases prices during these times relative to their level absent any new storage. A strong negative correlation between PV generation and generation from storage at high PV penetrations indicates storage is consistently charging when PV is generating and discharging otherwise. The increase in the value of $\mathrm{PV}$ above $5 \%$ penetration with low-cost storage is almost entirely due to the increase in the energy value of PV relative to the Reference scenario. The only other contributor to the increase in PV value is a decrease in the cost of DA forecast errors of less than $\$ 2 / \mathrm{MWh}$. The energy value of PV increases in part due to a reduction in PV curtailment from $2.9 \%$ with $30 \% \mathrm{PV}$ in the Reference scenario to less than $0.1 \%$ in the Low-cost Storage scenario.

\subsubsection{Further Considerations}

This analysis only considered one type of storage: PHS with 10 hours of reservoir capacity. The amount of energy that can be stored in the bulk power storage reservoir becomes increasingly important with higher penetrations of wind. Whereas the storage reservoir capacity is only a binding constraint 22 times during the year with $0 \%$ wind penetration, the reservoir capacity is a binding constraint 64 times with $30 \%$ wind. Since we only allow storage reservoir capacity to increase in proportion to storage generating capacity, the increase in the number of times that the storage reservoir is a binding constraint indicates that wind might benefit more from proportionally larger storage reservoirs. The relatively small increase in the value of wind with low-cost storage may also be due to the limited storage reservoir capacity.

In contrast to wind, the amount of energy that can be stored in the bulk power storage becomes less important with higher penetrations of PV. The reservoir capacity is only a binding constraint 13 times during the year with 
proportionally smaller reservoirs than the 10 hours of storage capacity assumed here and smaller reservoirs than would be ideal for wind. This is likely due to the diurnal profile of solar where storage would need to be charging for at most half of the day with high solar penetrations. In contrast wind is more variable over longer periods: high wind periods can last for multiple days, leading to a larger benefit from more storage reservoir capacity.

To achieve the benefits to wind and PV of bulk power storage, the cost of storage needs to be low. No additional pumped-hydro storage was built in the Reference scenario when storage costs were based on EIA cost estimates. Only by lowering the assumed investment cost for PHS did the model invest in new PHS. If an external policy measure (e.g., a storage subsidy or a utility requirement to invest in a certain amount of storage) were used to lower the market cost of storage, then this analysis would similarly be ignoring the cost of that subsidy or investment mandate.

485

Finally, the increase in the value of wind and PV with storage and the amount of storage added depend in part on the generation mix. The benefits of storage would likely be greater in regions with greater heterogeneity in variable costs of thermal generation plants than found for California where natural-gas fired power plants are usually on the margin.

\subsection{Real-Time Pricing}

In the Reference scenario, all electricity demand is assumed to be indifferent to the DA and RT wholesale market price. This is the situation in much of the United States, where customers pay retail rates that do not vary depending on actual conditions in the DA and RT markets. Increasingly, however, retail rates are including pricing signals to retail customers to indicate periods when electricity consumption is particularly expensive. Large industrial and commercial customers already participate in programs that subject them to prices in wholesale markets in some parts of the United States. Furthermore, the roll-out of smart meters that record demand at 15-minute intervals will enable small 
conditions in the wholesale market. The Real-Time Pricing (RTP) mitigation strategy assumes that load changes in response to wholesale power prices in both the day-ahead and real-time market.

Studies of customer demand when retail prices shift from static to dynamic wind. Implementation of RTP leads to $20 \%$ increase in the value of wind at

\footnotetext{
${ }^{5} \mathrm{~A}$ constant elasticity of -0.1 is within the range of assumptions used in other studies on the impact of RTP [e.g., 44, 27, 28.
} 
$40 \%$ penetration relative to the Reference scenario.

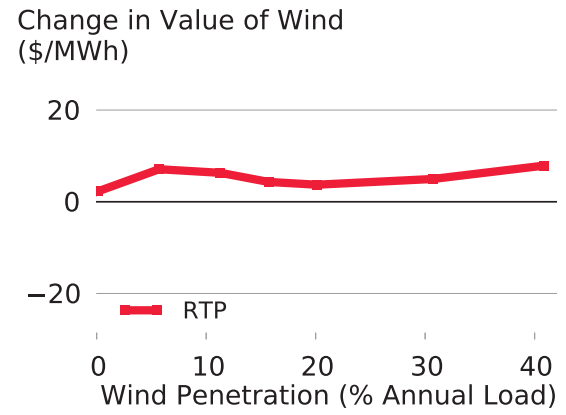

Figure 9: Change in the marginal economic value of wind with RTP and price-responsive demand relative to Reference scenario.

As with wind, implementing the RTP program increases the value of PV at high penetration levels; in contrast to wind, the RTP program decreases the value of $\mathrm{PV}$ at low penetration levels $(<5 \%)$, Figure 10 . At 10\% PV penetration, however, implementing RTP increases the value of PV by up to $\$ 10 / \mathrm{MWh}$. At even higher penetration levels, the increase in PV value from RTP is closer to $\$ 7-8 /$ MWh (a $29 \%$ increase in the value of $\mathrm{PV}$ at $30 \%$ penetration relative to the Reference scenario).

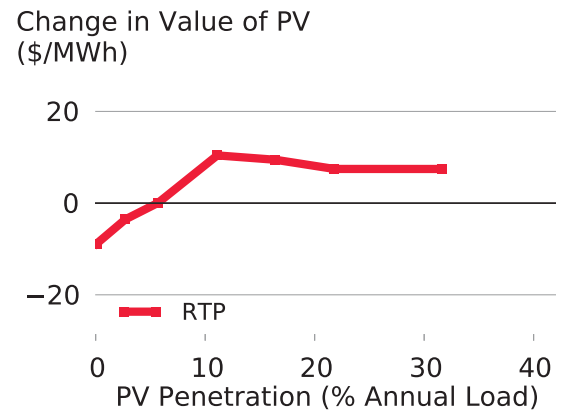

Figure 10: Change in the marginal economic value of PV with RTP and price-responsive demand relative to the Reference scenario. 


\subsubsection{Reasons for Change}

One of the most prominent changes observed in the long-run equilibrium with RTP is the change from infrequent but high price spikes with inelastic demand to more frequent but lower price spikes with elastic demand. With

inelastic demand, the prices jump to the administratively-set scarcity price when generation is unable to meet demand. Because these price spikes are so high they do not need to occur very frequently in order to justify the cost of building new generation capacity. With elastic demand, on the other hand, a rise in prices triggers some reduction in demand (therefore helping to maintain balance between the remaining demand and generation). Since the prices do not spike to as high of levels, the price spikes must occur more frequently to cover the cost of new generation investments.

The increase in value of wind with RTP is primarily due to an increase in the sum of the capacity and energy value of wind with increased penetration. The marginal value of wind increases because RTP tends to increase the load during times when wind power is available. The capacity value of wind increases because the increase in the number of hours with prices above $\$ 500 / \mathrm{MWh}$ happens to cover more hours with some wind generation. The energy value increases because price-responsive demand increases relative to historical levels during times with increased wind generation (due to wind's impact on depressing wholesale prices at these times leading to higher load with RTP and therefore and increase in wholesale prices relative to a case without RTP). In addition, wind curtialment is no longer needed, even at $40 \%$ wind penetration, with RTP which increases the energy value of wind. Less than $\$ 2 / \mathrm{MWh}$ of the increase in the marginal value of wind with RTP is due to a decrease in the cost of day-ahead forecast errors.

The reason for the decrease in PV value with RTP at low penetration is similar to the reason for the decrease in PV value with low-cost storage. Implementing RTP reduces the cost of capacity and the duration of very high price spikes. At low PV penetration, PV and the demand response from RTP are 
positively correlated, indicating that RTP decreases demand at the same time that $\mathrm{PV}$ is generating power. Lower demand leads to lower wholesale prices and therefore lowers the marginal value of $\mathrm{PV}$ at low penetration.

At $10 \% \mathrm{PV}$ penetration and above, PV and demand response are negatively correlated, indicating an increase in demand when PV is generating. At $30 \%$ penetration, the correlation between PV and demand response is substantially more negatively correlated than wind and demand response at $30 \%$ penetration. On average over the entire year, RTP increases the total demand by only $0.1 \%$ at $10 \% \mathrm{PV}$ penetration but by $3.2 \%$ at $30 \% \mathrm{PV}$ penetration. Nearly all of the increase in demand occurs during daytime hours when PV is producing power, particularly in spring months. The increase in demand while $\mathrm{PV}$ is generating increases the energy value of PV and obviates the need to curtail PV. A decrease in the cost of day-ahead forecast errors contributes less than $\$ 1 / \mathrm{MWh}$ to the increase in the marginal value of PV with RTP.

\subsubsection{Further Considerations}

The trends currently leading to the roll-out of smart meters and RTP programs are largely based on efforts to reduce peak demand, independent of mitigating changes in the economic value of wind and PV. This analysis indicates that, at low penetrations, wind and demand response occur at different times and PV and demand response occur at the same time (e.g, provide similar services). But with increasing wind or PV penetration, price-responsive demand increases during times with high wind or high PV generation. Contrary to most demand-response programs that have historically been designed to decrease demand, these results indicate that the value of wind or PV is increased by shifting demand to, or even increasing demand during, times when wind or $\mathrm{PV}$ are generating power. This conclusion is expected to apply to regions outside of California, though the particular generation patterns from wind and PV (and their correlation with load) may be different. Many other factors go into the design of demand-response and retail-pricing programs, but this analysis suggests that expectations for future wind or PV penetration levels might be 
an important consideration.

Demand-response strategies for peak-load days, such as pre-cooling, which shifts cooling loads away from the peak to earlier in the day, may need to be adjusted in scenarios with high PV penetration. At 0\% PV penetration, a precooling strategy would aim to reduce demand before around $6 \mathrm{pm}$ on peak-load days. With high PV penetration, the pre-cooling would need to reduce demand between about $6 \mathrm{pm}$ and $9 \mathrm{pm}$. High PV penetrations may also shift the focus from one customer class to another, depending on the load profiles of different customer classes. In some regions, commercial loads tend to peak earlier in the day while residential loads peak later in the evening. In that case, demandresponse programs could target commercial customers at low PV penetration but shift to residential customers at high PV penetrations. Such changes in consumption patterns may require end-use control technologies or customer behaviors that differ from those in traditional demand-response programs, which primarily reduce demand during summer afternoons. Midday electric vehicle charging might be well suited to increasing customer demand during times with high PV production.

\section{Conclusions}

Implementation of mitigation strategies has different impacts on marginal value depending both on the type of renewable technology (wind or PV) and the penetration level of that technology. A conclusion from this analysis is that one cannot assume that the effect of a mitigation strategy found for one technology at one penetration level will result in the same effect for a different technology or penetration level. A comprehensive analysis of the impact of several mitigation measures on both wind and PV, as presented in this paper, strengthens such a conclusion.

Another important finding is that although many of the mitigation strategies did increase the value of wind or PV relative to the unmitigated Reference scenario, none of them were able to fully maintain the value of wind or PV 
estimated at very low penetration levels.

The most effective combinations of mitigation strategies and renewable technologies at high penetration levels are as follows. The largest increases in the value of wind relative to the unmitigated Reference scenario at penetration levels above $20 \%$ occur with increased geographic diversity in wind sites, implementation of RTP for retail sales, and the availability of low-cost bulk power storage. The largest increases in the value of $\mathrm{PV}$ above $10 \%$ penetration occur with the availability of low-cost bulk power storage and RTP.

We also find interesting interactions between wind and PV in the technological diversity cases. In particular, various combinations of wind and PV do not decrease the value of wind or PV relative to the Reference scenario, even though the aggregate proportion of annual demand met by VG technologies is higher. Specifically, combinations of 10-20\% wind and 10\% PV have no lower value than wind alone. Similarly, combinations of 10-20\% PV with $10 \%$ wind have no lower value than PV alone. These results suggest that if $10-20 \%$ wind or PV penetrations can be economically justified on their own, then $30 \%$ penetration from combinations of wind and solar technologies would be similarly justified.

Throughout this analysis, only one mitigation measure is implemented at a time. In some cases, the benefits of different mitigation measures are caused by similar factors (e.g., increases in the value of wind at high penetration with ${ }_{64}$ RTP and storage are both linked to an increase in demand during times when wind is generating). As such, the change in the value of wind or PV from simultaneously implementing multiple mitigation measures is not expected to be the same as the sum of the change in value from each mitigation measure implemented in isolation. Interactions between mitigation measures is an area for future research.

The results presented here depend on many factors (correlation of load, wind, and $\mathrm{PV}$; mix of incumbent generators; etc.), some of which may be unique to California. The general framework used in this analysis can be applied elsewhere, though the particular results may differ. 


\section{Acknowledgements}

The work described in this paper was funded by the Office of Electricity Delivery and Energy Reliability (National Electricity Delivery Division) and by the Office of Energy Efficiency and Renewable Energy (Wind and Hydropower Technologies Office and Solar Energy Technologies Office) of the U.S. Department of Energy under Contract No. DE-AC02-05CH11231. For their support of this work, we thank Lawrence Mansueti, Patrick Gilman, Venkat Banunarayanan, and Kevin Lynn of the U.S. Department of Energy.

\section{References}

¿ [1] P. Sullivan, K. Eurek, R. Margolis, Advanced methods for incorporating solar energy technologies into electric sector capacity-expansion models: Literature review and analysis, Tech. Rep. NREL/TP-6A20-61185, National Renewable Energy Laboratory, Golden, CO (Jul. 2014).

URL http://www.nrel.gov/docs/fy14osti/61185.pdf

[2] S. Stoft, Power System Economics: Designing Markets for Electricity, Wiley/IEEE, 2002.

q [3] A. Mills, R. Wiser, An evaluation of solar valuation methods used in utility planning and procurement processes, Tech. Rep. LBNL-5933E, Lawrence Berkeley National Laboratory, Berkeley, CA (Dec. 2012).

URL emp.1bl.gov/sites/all/files/lbnl-5933e_0.pdf

[4] P. L. Joskow, Comparing the costs of intermittent and dispatchable electricity generating technologies, The American Economic Review 101 (3) (2011) 238-241. doi:10.1257/aer.100.3.238.

[5] IPCC, Summary for policymakers, in: O. Edenhofer, R. Pichs-Madruga, Y. Sokona, K. Seyboth, P. Matschoss, S. Kadner, T. Zwickel, P. Eickemeier, G. Hansen, S. Schlmer, C. von Stechow (Eds.), IPCC Special Report on Renewable Energy Sources and Climate Change Mitigation, Cambridge University Press, Cambridge, UK and New York, NY, USA, 2011. 
[6] R. Wiser, M. Bolinger, 2014 Wind technologies market report, Tech. Rep. DOE/GO-102014-4459, U.S. Department of Energy, Washington, D.C. (Aug. 2014).

[7] G. Barbose, N. Darghouth, S. Weaver, R. Wiser, Tracking the Sun VI: An historical summary of the installed cost of photovoltaics in the United States from 1998 to 2012, Tech. Rep. LBNL-6350E, Lawrence Berkeley National Laboratory, Berkeley, CA (Jul. 2013).

[8] L. Hirth, The market value of variable renewables: The effect of solar wind power variability on their relative price, Energy Economics 38 (2013) 218236.

[9] E. Baker, M. Fowlie, D. Lemoine, S. S. Reynolds, The economics of solar electricity, Annual Review of Resource Economics 5 (1) (2013) 387-426. doi:10.1146/annurev-resource-091912-151843.

[10] A. Mills, R. Wiser, Changes in the economic value of variable generation with increasing penetration levels: A pilot case study of California, Tech. Rep. LBNL-5445E, Lawrence Berkeley National Laboratory, Berkeley, CA (Jun. 2012).

[11] A. Mills, R. Wiser, Changes in the economic value of photovoltaic generation at high penetration levels: A pilot case study of California, IEEE Journal of Photovoltaics 3 (4) (2013) 1394-1402. doi:10.1109/JPHOTOV. 2013.2263984

[12] J. Luoma, P. Mathiesen, J. Kleissl, Forecast value considering energy pric705 ing in California, Applied Energy 125 (2014) 230-237. doi:10.1016/j. apenergy.2014.03.061.

[13] A. Mills, A. Botterud, J. Wu, Z. Zhou, B. M. Hodge, M. Heaney, Integrating solar PV in utility system operations, Tech. Rep. ANL/DIS-13/18, Argonne National Laboratory, Argonne, IL (Oct. 2013). URL http://www.osti.gov/scitech/biblio/1107495 
[14] A. Mills, R. Wiser, Changes in the economic value of wind energy and flexible resources at increasing penetration levels in the Rocky Mountain Power Area, Wind Energy 17 (11) (2014) 1711-1726. doi:10.1002/we. 1663 .

[15] J. F. DeCarolis, D. W. Keith, The economics of large-scale wind power in a carbon constrained world, Energy Policy 34 (2006) 395-410.

[16] W. Kempton, F. M. Pimenta, D. E. Veron, B. A. Colle, Electric power from offshore wind via synoptic-scale interconnection, Proceedings of the National Academy of Sciences 107 (16) (2010) 7240-7245.

[17] C. L. Archer, M. Z. Jacobson, Supplying baseload power and reducing transmission requirements by interconnecting wind farms, Journal of Applied Meteorology and Climatology 46 (2007) 1701-1717.

[18] C. Obersteiner, M. Saguan, Parameters influencing the market value of wind power: A model-based analysis of the central european power market, European Transactions on Electrical Power 21 (6) (2011) 1856-1868.

[19] C. Budischak, D. Sewell, H. Thomson, L. Mach, D. E. Veron, W. Kempton, Cost-minimized combinations of wind power, solar power and electrochemical storage, powering the grid up to $99.9 \%$ of the time, Journal of Power Sources 225 (2013) 60-74.

[20] A. D. Lamont, Assessing the long-term system value of intermittent electric generation technologies, Energy Economics 30 (2008) 1208-1231.

[21] P. Tafarte, S. Das, M. Eichhorn, D. Thrän, Small adaptations, big impacts: Options for an optimized mix of variable renewable energy sources, Energy 72 (2014) 80-92. doi:10.1016/j.energy . 2014.04.094.

735 [22] R. Sioshansi, Increasing the value of wind with energy storage, The Energy Journal $32(2)$. 
[23] P. Denholm, R. M. Margolis, Evaluating the limits of solar photovoltaics $(\mathrm{PV})$ in electric power systems utilizing energy storage and other enabling technologies, Energy Policy 35 (9) (2007) 4424-4433.

[24] M. G. Rasmussen, G. B. Andresen, M. Greiner, Storage and balancing synergies in a fully or highly renewable pan-European power system, Energy Policy 51 (2012) 642-651.

[25] A. Tuohy, M. O'Malley, Pumped storage in systems with very high wind penetration, Energy Policy 39 (4) (2011) 1965-1974.

[26] A. Lamont, Assessing the economic value and optimal structure of largescale electricity storage, IEEE Transactions on Power Systems 28 (2) (2013) 911-921.

[27] R. Sioshansi, W. Short, Evaluating the impacts of Real-Time pricing on the usage of wind generation, IEEE Transactions on Power Systems 24 (2) (2009) 516-524.

[28] C. De Jonghe, B. Hobbs, R. Belmans, Optimal generation mix with shortterm demand response and wind penetration, IEEE Transactions on Power Systems 27 (2) (2012) $830-839$.

[29] S. Jin, A. Botterud, S. Ryan, Impact of demand response on thermal generation investment with high wind penetration, IEEE Transactions on Smart Grid 4 (4) (2013) 2374-2383. doi:10.1109/TSG.2013.2278882.

[30] M. Nicolosi, The economics of renewable electricity market integration: An empirical and model-based analysis of regulatory frameworks and their impacts on the power market, Doctoral thesis, Universität zu Köln (2012).

[31] L. Hirth, F. Ueckerdt, The decreasing market value of variable renewables: Integration options and deadlocks, in: D. Stolten, V. Scherer (Eds.), Transition to Renewable Energy Systems: Energy Process Engineering, Wiley, 2013. 
[32] A. Mills, R. Wiser, Strategies for mitigating the reduction in economic

William W. Hogan, On an "energy only" electricty market design for resource adequacy, Tech. rep., John F. Kennedy School of Government,

[34] Energy Information Administration (EIA), Annual Energy Outlook, 2011, Washington, DC: US.

[37] M. Fripp, Switch: A planning tool for power systems with large shares of intermittent renewable energy, Environmental Science \& Technology 46 (11) (2012) 6371-6378. doi:10.1021/es204645c.

[38] Eagle Crest Energy, Eagle Mountain pumped storage project draft license statement initial application, Application P-13123, Federal Energy Regulatory Commission, Palm Desert, California (Jun. 2008).

[39] T. N. Taylor, P. M. Schwarz, J. E. Cochell, 24/7 hourly response to electricity real-time pricing with up to eight summers of experience, Journal of Regulatory Economics 27 (3) (2005) 235-262.

790

[40] M. G. Lijesen, The real-time price elasticity of electricity, Energy Economics 29 (2007) 249-258. 
[41] R. N. Boisvert, P. Cappers, C. Goldman, B. Neenan, N. Hopper, Customer response to RTP in competitive markets: A study of Niagara Mohawk's standard offer tariff, The Energy Journal 28 (1) (2007) 53-74.

[42] J. Zarnikau, I. Hallett, Aggregate industrial energy consumer response to wholesale prices in the restructured Texas electricity market, Energy Economics 30 (4) (2008) 1798-1808.

[43] H. Allcott, Rethinking real-time electricity pricing, Resource and Energy Economics 33 (4) (2011) 820-842. doi:16/j.reseneeco.2011.06.003.

800 [44] S. Borenstein, S. Holland, On the efficiency of competitive electricity markets with time-invariant retail prices, The RAND Journal of Economics 36 (3) (2005) 469-493. 


\section{Graphical Abstract}

\section{Marginal Economic Value (\$/MWh) \\ 100}

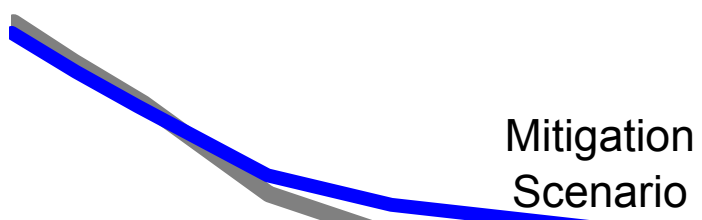

Reference

Scenario

Change in Value with Mitigation

Measure

0

0 